\title{
Prevalence of cesarean section and associated factor among women who give birth in the last one year at Butajira General Hospital, Gurage Zone, SNNPR, Ethiopia, 2019
}

\begin{abstract}
Background: Caesarean section is an operational procedure whereby the fetus, placenta, and membrane after the end of the 28th week is delivered through an incision on the abdominal and uterine walls. This does not include delivery through an abdominal incision of a fetus lying free in the abdominal cavity following uterine rupture or in secondary abdominal pregnancy.

Objective: To assess the prevalence of cesarean section delivery and associated factors among women who give birth one last year in Butajira General Hospital on April 1-15, 2019

Methods: Institution based retrospective cross-section study was employed among 250 patient charts in Butajira General Hospital from April 1-15, 2019. A systematic random sampling technique was used. A record review was used to collect the data. The data were entered into Epi data version 3.1 and exported to SPSS version 24 for analysis. All variables with $\mathrm{P}<0.25$ in the bivariate analysis were included in the final model and statistical significance was declared at $\mathrm{P}<0.05$.

Conclusion: Therefore, the overall magnitude of the cesarean section is above the world health organization's; appropriate indication must be assessed before proceeding to the procedure. Rural residence, fetal weight greater than $2500 \mathrm{gm}$ and previous history of stillbirth were independent predictors of cesarean section.. And minimizing stillbirth by helping the women to attend maternal and child health clinics during her course of pregnancy and the postpartum period that decreases her fear and stress due to bad history.
\end{abstract}

Volume 6 Issue I - 2020

\author{
Solomon Shit,' Asefa Shifera, ${ }^{2}$ Rahima Eyado, ${ }^{2}$ \\ Hawi Tadesa, ${ }^{2}$ Aberash Beyene ${ }^{1}$ \\ 'Wolkite University College of Health and Medical Sciences, \\ Ethiopia \\ ${ }^{2}$ Wolkite University Comprehensive Specialised Hospital, \\ Ethiopia
}

Correspondence: Solomon Shitu, Wolkite University College of Health and Medical Sciences, Ethiopia,

Email solomonsht@gmail.com

Received: January 06, 2020 | Published: February 07, 2020

Keywords: cesarean section, postpartum mother, Butajira

Abbreviations: ANC, antenatal care; APH, ant partum hemorrhage; CPD, cephalic pelvic disproportion; CS, cesarean section; EDHS, Ethiopia demographic health; MMR, maternal mortality rate; NMR, neonatal mortality rate; OL, obstruct labor; PROM, pre rupture of membrane; SDG, sustainable development goal; SNNP, South Nation nationality people; USA, United State of America; WHO, world health organization

\section{Background}

Cesarean section is an operational procedure whereby the fetus after the end of the 28th week is delivered through an incision on the abdominal and uterine walls. The increase in the CS rate was appreciated to be an American problem is becoming now an international crisis. Cesarean section is rising from $29 \%$ to $30.5 \%$ in 2004 to 2008 United States. ${ }^{1-4}$ Cesarean section was performed for many varieties of indications and associated factors. ${ }^{5}$ In pregnancies complicated by fetal malpresentation, excessive fetal growth, multiple gestation, cord prolapsed, placenta abruption, age of the mother, educational level and different of maternal infection. ${ }^{6}$

World Health Organization (WHO) the cesarean section delivery recommended rate was $10 \%$ to $15 \%$ according to $2015 .^{7-10} \mathrm{~A}$ systematic review and ecological analysis were performed and concluded that at the population level, CS rates higher than $10 \%$ were not associated with the reductions in maternal and newborn mortality rates. ${ }^{11}$ Worldwide, ${ }^{12}$ approximately 830 women died every single day due to complications during pregnancy or childbirth in $2015 .{ }^{13}$ Reducing the global maternal mortality ratio (MMR) from 216 per 100000 live births in 2015 to less than 70 per 100000 live births by 2030 (SDG). ${ }^{14}$ According to Mini EHDS 2019 in Ethiopia MMR are 353 deaths per 100,000 live births. ${ }^{15}$

The CS is the most common surgical operation estimated prevalence of $33 \%$, but varies from country to country in china is $46 \%$ and $25 \%$ in the Asian, European and USA 30.5\%. ${ }^{16}$ The prevalence ranges from $7.3 \%$ in Africa and $40.5 \%$ in Latin America and the Caribbean. ${ }^{17-19} \mathrm{An}$ increase in the primary CS delivery with no specified indication was faster than in the overall population and appears to be the result of changes in obstetrics practice rather than changes in the medical risk profile or increases in maternal request. ${ }^{20}$ The CS was performed without the medical indication has increased the risk of maternal and neonatal mortality when we compare with the spontaneously vaginal delivery. ${ }^{21,22}$ Also, elective CS had a 2.84 fold greater chance maternal death as compared with vaginal delivery. In the United Kingdom two-fold increased maternal mortality with CS was detected. ${ }^{23}$ Those are recurrent CS, hysterectomy, maternal and fetal death. ${ }^{24}$ Previous CS increases the risk of the multiple placenta abnormalities like placental abruption, placenta previa, and adherent placenta in subsequent pregnancies. ${ }^{24}$ First birth with a single CS 
scar 30\% increases the risk of placental abruption in the subsequent pregnancies. ${ }^{25}$ In addition to this, women who have less than four spontaneously vaginal delivery with single previous CS scar has 1.7 fold increase the risk of placental previa whereas women who have four or more than four spontaneously vaginal delivered with single previous CS scar delivery nine-fold increased the risk of placental previa. $^{25-27}$

Babies are also vulnerable to unnecessary risk from rising off the CS prevalence. The first danger to the baby is $1 \%$ to $9 \%$ enhance the surgeon to accidentally lacerate $6 \%$ of non-vertex presentation among non-vertex presentation fetus. ${ }^{28-34} \mathrm{~A}$ previously done systematic review found that the cost of cesarean delivery is about twice the cost of a vaginal delivery. ${ }^{35}$ Also, there is an increased risk of adverse effects with cesarean section, particularly if the medical complication does not sever. ${ }^{36}$ Therefore, this study was aimed to assess the prevalence and associated factors with CS delivery in Butajira General Hospital Gurage Zone.

\section{Methods}

\section{Study design, area and period}

The institution-based retrospective cross-section study design was conducted from April 15 to May 10, 2019, in Butajira General Hospital secondary data from a one-year chart review. It is found in the Butajira town of the Gurage zone, SNNPR. The town is located at $143 \mathrm{~km}$ from Addis Ababa the capital city of Ethiopia and $163 \mathrm{~km}$ from Hawassa capital of SNNPR. Based on the 2007 Central Statistics Agency of Ethiopia the total estimation of Butajira 33,406, of whom 16,923 are male and 16,483 a town population were female. There are one Hospital and one health center. The Hospital is composed of 5 specialists, 17 general practitioners, 4 public officers, 3 emergence surgeons, 83 nurses, 17 Midwives, 19 pharmacists, 14 laboratory technicians, 2 radiologists, 5 anesthesia professionals, 8 healthy information technology and 3 psychiatric nurses. Hospital's maternal and child health unit monthly report indicates there are 250-300 deliveries, 250 ANC follow up, 200 postnatal care, 200 immunization (Butajira Hospital annual report, 2017).

Source population: All charts of the mother who gave birth in the last one year at Butajira General Hospital.

Study population: All randomly selected charts of the women who give birth in the last one year at Butajira General Hospital.

\section{Eligibility criteria}

Inclusion criteria: All charts of the women who gave birth after the fetus are viable.

Exclusion criteria: Incomplete charts.

\section{Sampling size determination}

The separate sample size was calculated for each specific objective by using both single and double population proportion and total calculated. The sample size of the first objective was greater than that of the second objective. If so the final sample size was come up by adding a non-response rate of $10 \%$ to the larger sample size from the first objective which is 227 . So, the calculated sample size for this study was 250 .

\section{Sampling procedure}

A systematic random sampling method was used.
The total number of women delivered in the last one year in Butajira General Hospital was 3054 so calculates the $\mathrm{K}$ value was 12.216. So, we took every 12 intervals from the registration card until the total sample size.

\section{Variable}

Dependent variable: Cesarean section delivery.

Independent variable

I. Socio-demographic factor

II. Obstetrics factor

III. Maternal and fetal factor

IV. Medical complication

\section{Operational definition}

a. Incompletes chart is the patient card that has not contained all components filled according to the chart needed. ${ }^{37}$

b. Cesarean section is the expulsion of the fetus, membrane, and placental by incision both abdomen and uterus.

\section{Data collection method}

Mothers' socio-demographic characteristics, economic status was adapted from the Ethiopian Demographic and Health Survey (EDHS) 2016 (EDHS, 2016). The questionnaire's other factors were developed by reviewing different kinds of literature. The data collectors have collected the data by reviewing patient charts after checking its completeness.

\section{Data quality control}

To ensure quality, the questionnaire was prepared in the English language. The questionnaire was checked for completeness before data entry into the software. Proper coding and categorization of data were maintained for the quality of the data to be analyzed. Double data entry was done for its validity and compare to the original data. Two days of training were given for data collectors about the purpose, the benefits and the risks of the study and how to collect the data by investigators.

\section{Data processing and analysis procedure}

The data was cleaned, coded, entered and entered into Epi data version 3.1 to minimize logical errors, then the data was exported to SPSS window version 24 for analysis. The analysis was done by computing proportions and summary statistics. Then, the result was presented by table frequency, percentage and pie chart. Bivariate analysis and multivariate analysis were computed to see the association between each independent variable and the outcome variable by using binary logistic regression. The assumptions for binary logistic regression were checked and values below 0.25 in the Bivariate analysis were considered as candidate variables for multivariate logistic regression to control all possible confounders. Adjusted odds ratios with their $95 \%$ confidence intervals and p-value of less than 0.05 were considered to have significant associated factors with CS.

\section{Results}

\section{Socio-demographic characteristics}

In this study, a total of 248 patient's cards were reviewed making a response rate of $99.2 \%$. The age of the study participants ranged from 
17 to 44 years. The mean age of the participants was $27.63(\mathrm{SD} \pm 5.1)$ years. The majority of participants $164(65.8 \%)$ were between $20-30$ years old. Almost all $98 \%$ of participants were married. As a resident status, two-third of participant $164(66.1 \%)$ were rural residents. Majority of women's occupation was housewife (Table 1).

\section{Obstetric characteristic}

Among the total study subjects more than half $155(62.5 \%)$ were gravid two and three followed by primigravida $48(19.4 \%)$. About three fourth had ANC follow up at least once in their current pregnancy. Eighty-five percent (212) of study subjects were a term at the time of delivery, $22(8.9 \%)$ preterm and $14(5.6 \%)$ post-term. Only $4(1.6 \%)$ of participants had a previous history of stillbirth and $21(8.5 \%)$ had a history of abortion. Nearly all (98.8\%) had documented partograph. From those who undergo cesarean section one-third 37(71.15) of them, the procedure was done due to fetal indication. More than twothirds $(69.7 \%)$ of women undergo SC was due to maternal indication and the remaining $30.3 \%$ was due to fetal indication (Table 2 ).

Table I Sociodemographic characteristics of women who gave birth in Butajira General Hospitals, Butajira, Ethiopia 2019, $(n=248)$

\begin{tabular}{llll}
\hline Variable & Classification & Frequency & Percentage (\%) \\
\hline Age & $<19$ & 1 & 0.4 \\
& $20-24$ & 72 & 29 \\
& $25-29$ & 98 & 39.5 \\
& $30-34$ & 49 & 19.75 \\
Marital status & $\geq 35$ & 28 & 11.29 \\
\multirow{3}{*}{ Residence } & Married & 243 & 98 \\
\multirow{3}{*}{ Occupation of women } & Single & 5 & 2 \\
& Rural & 164 & 66.1 \\
& Urban & 84 & 33.9 \\
& Housewife & 93 & 37.5 \\
& Merchant & 52 & 21.96 \\
& Government employer & 56 & 22.6 \\
& Farmer & 39 & 17.72 \\
& Daily laborer & 8 & 3.22 \\
\hline
\end{tabular}

Table 2 Obstetric characteristics of women who gave birth in Butajira general hospital, Butajira, Ethiopia 2019, n=248

\begin{tabular}{|c|c|c|c|c|}
\hline \multirow[b]{2}{*}{ Variable } & \multirow[b]{2}{*}{ Classification } & \multicolumn{3}{|c|}{ Cesarean section } \\
\hline & & Yes & No & Frequency (\%) \\
\hline \multirow[t]{3}{*}{ Gravid } & One & $5(9.6)$ & $42(21.4)$ & $47(19.4)$ \\
\hline & Two-Three & $38(73.1)$ & $118(60.2)$ & $156(62.5)$ \\
\hline & Greater Three & $9(17.3)$ & $36(18.5)$ & $45(18.1)$ \\
\hline \multirow[t]{3}{*}{ Parity } & I & $\mathrm{II}(2 \mid .2)$ & $75(38.3)$ & $86(34.7)$ \\
\hline & 2 & $35(67.3)$ & $95(48.5)$ & $130(52.4)$ \\
\hline & $\geq 3$ & $6(11.5)$ & $26(13.5)$ & $32(12.9)$ \\
\hline \multirow[t]{2}{*}{ Previous miscarriage } & Yes & $6(11.5)$ & $15(7.7)$ & $21(8.5)$ \\
\hline & No & $46(88.5)$ & $181(92.3)$ & 227(91.5) \\
\hline \multirow[t]{2}{*}{ Previous stillbirth } & Yes & $6(11.5)$ & $6(3.1)$ & $12(4.8)$ \\
\hline & No & $46(88.5)$ & 190(96.9) & $236(95.2)$ \\
\hline \multirow[t]{3}{*}{ Gestational age at delivery } & $<37$ Week & $2(3.8)$ & $20(10.2)$ & $22(8.9)$ \\
\hline & 37-42 Week & $48(92.2)$ & 164(83.7) & $212(85.5)$ \\
\hline & $>42$ Week & $2(3.8)$ & $12(6.1)$ & $14(5.6)$ \\
\hline \multirow[t]{2}{*}{ Antenatal care follow up } & Yes & $36(69.2)$ & $149(76)$ & $185(74.6)$ \\
\hline & No & 16(30.8) & $47(24)$ & $63(25.4)$ \\
\hline \multirow[t]{3}{*}{ Fetal weight } & $<2500$ & $4(7.7)$ & $53(27)$ & $57(23)$ \\
\hline & $2500-4000$ & $39(75)$ & $|4|(7 \mid .9)$ & $180(72.6)$ \\
\hline & $>4000$ & $9(17.3)$ & $2(I)$ & II(4.4) \\
\hline
\end{tabular}




\section{Prevalence of cesarean section}

The overall prevalence of CS in the study setting was 52(21\%). Among $33(13.3 \%)$ of the mothers had primary CS while $19(7.7 \%)$ had repeat CS. Cesarean section was performed for emergency reasons in 34(13.7\%), whereas elective CS 18 (7.3\%) of cases.

\section{Associated factors of cesarean section}

Variables that fulfill the criteria in Bivariate analysis were residence, previous stillbirth, fetal weight, and gestational age.
This variable was entered into a multivariate logistic regression model from that fetal weight; previous stillbirth and residence were statistically associated with CS after adjusting for other variables in the final model. Mothers, who were living in a rural area, were 2.5 times more likely to undergo CS as compared with urban mother AOR $2.504,95 \%$ CI $(1.158,5.414)$. From study participants who had the previous history of stillbirth were 5.5 times more likely to undergo CS than their counterparts AOR 5.49 95\%CI (1.496-20.179). Mothers whose fetal weight was (2500-4000)gm, were 5.3 times more likely to undergo CS were as compared with those whose fetal weight is less than to $2500 \mathrm{gm}$ AOR $5.344,95 \% \mathrm{CI}(1.683,16.972)$ (Table 3).

Table 3 Factors associated with cesarean section delivery in bivariate and multivariate logistic regression among women who gave birth in, Butajira general hospital, Ethiopia 2019

\begin{tabular}{|c|c|c|c|c|c|}
\hline \multirow[t]{2}{*}{ Variable } & \multirow[b]{2}{*}{ Classification } & \multicolumn{2}{|c|}{ Caesarean- section } & \multicolumn{2}{|l|}{$95 \% \mathrm{Cl}$} \\
\hline & & Yes (\%) & No (\%) & Crud OR & Adjusted OR \\
\hline \multirow[t]{2}{*}{ Residence } & Urban & $73(37.2)$ & $\mathrm{II}(2 \mathrm{I} .2)$ & 1 & 1 \\
\hline & Rural & $123(62.8)$ & $4 I(78.8)$ & $2.2 \mathrm{I}(\mathrm{I} .02-4.57)$ & $2.62(1.229-5.584)^{*}$ \\
\hline \multirow[t]{3}{*}{ Gestational age } & $<37$ & $2(3.8)$ & $20(10.2)$ & 1 & 1 \\
\hline & $37-4 I$ & $48(92.2)$ & I64(83.7) & $2.93(0.66-12.97)$ & $1.25(0.25-6.30)$ \\
\hline & $>42$ & $2(3.8)$ & $12(6.1)$ & $1.67(0.21-13.43)$ & $0.58(0.06-5.49)$ \\
\hline \multirow[t]{2}{*}{ Fetal weight } & $<2500$ & $4(7.7)$ & $53(27)$ & I & I \\
\hline & $2500-4000$ & $48(92.3)$ & I43(73) & $4.45(I .53-12.94)$ & $5.54(1.72-17.84) * *$ \\
\hline \multirow[t]{2}{*}{ Previous stillbirth } & Yes & $6(11.5)$ & $6(3.1)$ & I & 1 \\
\hline & No & $46(88.5)$ & $190(96.9)$ & $4.13(1.27-13,39)$ & $5.49(1.495-20.179)^{* * *}$ \\
\hline
\end{tabular}

*Significant with $\mathrm{P}=0.013$, * Significant with $\mathrm{P}=0.004, * *$ Significant with $\mathrm{P}=0.0 \mathrm{I}$

\section{Discussion}

In this study, the prevalence of CS in Butajira general hospital was 21\% (95\%CI: 16.5-26.2). Residence, previous stillbirth, fetal weight, and gestational age were candidate variables for multivariate analysis. Residence, previous history of stillbirth and fetal weight were statistically associated with cesarean section. In this study about onefifth of women who admitted for delivery undergo a cesarean section. This finding was in line with studies done in Eastern Ethiopia Harar (26.6\%) and north Thailand (23.6\%). ${ }^{38-44}$ The result was slightly higher than studies done in Tikur Anbessa hospital (10\%), Jimma University specialized Hospital (8\%), Felegehiwot referral hospital $9.7 \%$ South Africa (15.4\%), Namibia (13\%), and World Health Organizations recommendation that one country has to perform cesarean section. 26,36,40-42,45 This may be due to increased accessibility and patients desire to have a cesarean section. But this finding was slightly lower than the study was done in Atata Hospital (27.6\%), USA (30.5\%) and China (46\%). ${ }^{37,46-52}$ The possible reason for the discrepancy may be methodological differences and differences in study area and period.

Mothers, who were living in rural areas, were 2.5 times more likely to undergo CS as compared with urban mother AOR 2.504, $95 \%$ CI $(1.158,5.414)$. This result is in line with the study Felege hiwot referral Hospital Amhara regional state Ethiopia. ${ }^{52}$ The reason may be due to women who live in rural areas were delay to arrive or to seek care at health institution and they arrive health institutions after a complication occurred and health professionals directly decide to have a cesarean section.
Mothers whose fetal weight was (2500-4000)gm, were 5.3 times more likely to undergo CS were as compared with those whose fetal weight is less than to $2500 \mathrm{gm}$ AOR $5.344,95 \% \mathrm{CI}(1.683,16.972)$. This finding is in line with studies done in India, two studies in Ethiopia Harar and Felegehiwot referral hospital. ${ }^{52}$ This may be due to when the weight of the fetus is large there is an increased chance of cephalopelvic disproportion and obstructed labor that may are absolute indications for cesarean section.

From study participants who had the previous history of stillbirth were 5.5 times more likely to undergo CS than their counterparts AOR 5.49 95\%CI(1.496-20.179). This finding is similar to the study done in Iran. This may be since women who have the previous history stillbirth had fear of losing her current baby so to avoid this she needs to have a cesarean section. Also, the fact that there may be stress and that will predispose her to develop complications that lead to cesarean section. The study was done by reviewing charts so some variables cannot access.

\section{Conclusion}

The overall magnitude of the cesarean section is above the world health organization's recommendation so it is better detect appropriate indication for cesarean section before the procedure. Rural residence, fetal weight greater than $2500 \mathrm{gm}$ and previous history of stillbirth were independent predictors of cesarean section. And minimizing stillbirth by helping the women to attend maternal and child health clinics during her course of pregnancy and the postpartum period that decreases her fear and stress due to bad history. 


\section{Ethics approval and consent to participate}

Ethical clearance was obtained from Wolkite University, College of Health and Medical Sciences, Institutional Health Research Ethics Committee. A formal letter for permission and support was written to the zonal health department of Guraghe from University, and then from the zone health department to Butajira General Hospital. Also, the study did not involve any invasive procedures. Moreover, the confidentiality of information was guaranteed by using code numbers rather than personal identifiers and by keeping the data locked.

\section{Acknowledgments}

The content of the study is solely the responsibility of the authors.

\section{Conflicts of interest}

The authors declare that they have no conflict of interests.

\section{Funding}

None of the author of this article have received any funding.

\section{References}

1. Arulkumaran S. Obstetric Proceeding. In: D Keith, editor. Dewhurst's Textbook of Obstetrics and Gynecology. 7th ed. United States: Edmonds Blackwell publishing; 2007.

2. Souza JP, Gülmezoglu A, Lumbiganon P, et al. WHO Global Survey on Maternal and Prenatal Health Research Group, et al. Caesarean section without medical indications is associated with an increased risk of adverse short-term maternal outcomes: the 2004-2008 WHO Global Survey on Maternal and Prenatal Health. BMC Med. 2010;8:71.3

3. World Health Organization. Global Survey on Maternal and Prenatal Health Research Group; 2005.

4. Hemminge E, Merilainen J. Long term effects of cesarean sections: Ectopic pregnancies and placental problems. AM J Obstet Gynecol. 1996;174:1569-1574.

5. Green JE MacLean F, Usher SR. Cesarean section study of Latin American Hospital. Am J Obstet Gynecol. 1982. 142 p.

6. Magnan EF: Winchester MI. Factors adversely affecting pregnancy outcomes. Am J prenatal. 1995;12:464.

7. Notion FC, Cnattingius S, Bergson p, et al. Cesarean section delivery in the 1980s: international comparison by indication. Am J Obstet Gynecol. 1994;179(2):495-504

8. Hankins GD, Clerk SM, Munn MB. Cesarean section on reques at 39 weeks: impact on shoulder dystopia, fetal trauma, neonatal encephalopathy, and intrauterine fetal demise. Seminperinatol. 2006;30(5):276-287.

9. Sakala EP, Andree I. Optimal route of delivery for meningomyelocele Obstet Gynecol Surv. 1990;45(4):209-212.

10. World Health Organzation. WHO statement of on the cesarean section rates: WHO/RHR/15.02:Geneva:WHO; 2015.

11. Betran Ap, Torloni MRJ, Yu J, et al, what is optimal cesarean section at the population level? A systematic review ecological studies. Reprod Health. 2015;12:57

12. Ethiopia, Mini Demographic and Health Survey, Addis Ababa; 2016.

13. Trends in maternal mortality: 1990 to 2015. Estimates by WHO, UNICEF, UNFPA, World Bank Group and the United Nations Population Division. Geneva: World Health Organization; 2015.
14. Alkema L, Chou D, Hogan D, et al. Global, regional, and national levels and trends in maternal mortality between 1990 and 2015, with scenario-based projections to 2030: a systematic analysis by the UN Maternal Mortality Estimation Inter-Agency Group. Lancet. 2016;387(10017):462-474.

15. Levels \& Trends in Child Mortality. Report 2015. Estimates developed by the UN Inter-agency Group for Child Mortality Estimation. United Nations Children's Fund, World Health Organization, World Bank and United Nations. New York (NY): United Nations Children's Fund; 2015.

16. Betray AP, Mealtime, Lauer JA, et al. Rates of Caesarean Section: Analysis of Global, Regional and national estimates. Paediatr Perinat Epidemiol. 2007;21(2):98-113.

17. WHO global database on maternal health indicators, Geneva; 2017.

18. Central Statistical Agency (CSA): Ethiopia and ICF. 2016.

19. José Villar, Guillermo Carroli, Nelly Zavaleta, et al. Maternal and neonatal individual risks and benefits associated with caesarean delivery: multicentre prospective study. BMJ. 2007;335:1025.

20. Harper MA, Byington RP, Espeland MA, et al. Pregnancy related death and health care services. Obstetrics Gynecol. 2003;102(2):273-278.

21. Hamilton BE, Martin JA, Sutton PD. Births: preliminary data for 2003. Natal Vital Stat Rep. 2004;53(9):1-17.

22. Bentran AP, Marialdi M, Laver JA, et al. Rate of $\mathrm{c} / \mathrm{s}$ : analysis of global regional and national estimates . Paediatr Perinat Epidemiol. 2007;21(2):98-113.

23. Marfatlal SJ, Narendrabhi MM. Analysis of mode of delivery in women with previous one cesarean section. J Obstet Gynecol India. 2009;59(2):136-139.

24. Zelop C, Heffner LJ. The downside of the cesarean delivery: short and long term complication. Clin Obstet Gynecol. 2004;47(2):386-393.

25. Sur S, Mackenzie's IZ. Does discussion of possible scar influence preferred mode of delivery after the cesarean section. Journal of Obstetrics and Gynaecology. 2005;25(4).

26. Collin SM, Marshall T, Filippi V. Cesarean section delivery and subsequent fertility in sub $\square$ Saharan Africa. BJOG. 2006;116(3):276283.

27. Mollison J, Porter M, Campbell D, et al. Primary mode of delivery and subsequent pregnancy. BJOG. 2005;112(8):1061-1065.

28. Maymon R, Halperin R, Mendlovic S, et al. Ectopic pregnancy on the cesarean section scar. Human Reproduction Update. 2004;10(6):515523.

29. Victor CG, Horta BL. Evidence long term effect of the breastfeeding. 2007.

30. Moore ER, Anderson Chet, Bergman N, et al. Early skin to skin contact for the mother and their healthy of infant. Cochrane Database Syst Rev. 2012;5:CD003519.

31. Marfatlal SJ, Narendrabhi MM. Analysis of mode of delivery in women with previous one cesarean section. J Obstet Gynecol India. 2009;59(2):136-139.

32. Hewick C. Repeat cesarean delivery optimal before 39 weeks. Meds cape medical news. 2014.

33. Tori kolas, Dag Hofoss, Anne K Daltveit, et al. Indications for cesarean deliveries in Norway. American Journal of obstetrics and gynecology. 2003; 188:864-870.

34. Henderson J, McCandlish R, Kumiega L, et al. Systematic review of economic aspects of alternative modes of delivery. BJOG. 2001;108(2):149-157. 
35. Ecker JL, Frigoletto FD Jr. Cesarean delivery and the risk-benefit calculus. N Engle J Med. 2007 356(9):8858

36. Hemminge E, Merilainen J. Long term effects of cesarean sections: Ectopic pregnancies and placental problems. Am J Obstet Gynecol. 1996;174(5):1569-1574.

37. World Health Statistics. Part III. Global Health Indicators; 2012.

38. Samsone Gebremedhine. Trend and socio-demographic differential of cesarean section in Adiss Ababa, Ethiopia. Reproductive Health. 2014.

39. Tadesse E, Adane M, Abiyou M. Caesarean section deliveries at Tikur Anbessa Teaching Hospital, Ethiopia. East Afr Med J. 1996;73(9):619622.

40. Subhashini R, Umea N. Changing trends in caesarean delivery. IAIM 2015;(2)(3):96-02

41. Linn Belcher, SirilStokke. Indications used for CS in St. Joseph Medical Hospital in Moshe, Tanzania; 2013.

42. Moges A, Ademe B, Akessa G, Prevalence and Outcome of Caesarean Section in Attat Hospital, Garage Zone, SNNPR, Ethiopia. Arch Med. 2015;7(4):1-6.

43. Soto-Vega E, Casco S, Chamizal K, et al. Rising Trends of Cesarean Section Worldwide: A Systematic Review. Obstet Gynecol Int J. 2015;3(2):260-265.

44. Suzuki S, Nakata M. Factors Associated with the Recent Increasing Caesarean Delivery Rate at Japanese Prenatal Center. ISRN Obstet Gynecol. 2013:863282.
45. Bayou YT, Machala YJS, Thupayagale-Tshweneagae G. Patterns of caesarean-section delivery in Addis Ababa, Ethiopia. Afr J Prim Health Care Fame Med. 2016;8(2):e1-e6.

46. Gebremedhin S. Trend and socio-demographic differentials of Caesarean section rate in Addis Ababa, Ethiopia: analysis based on Ethiopia demographic and health surveys data. Reprod Health. 2014;11(1):14.

47. Neumann M, Adcock G, Azad Kieta, et al. Prevalence and determinants of caesarean section in private and public health facilities in underserved South Asian communities: cross-sectional analysis of data from Bangladesh, India and Nepal. BMJ Open. 2014;4(12): e005982.

48. Tsega F, Manistee B, Desire Y, et al. Prevalence of Caesarean Section in Urban Health Facilities and Associated Factors in Eastern Ethiopia: Hospital Based Cross Sectional Study. J Prig Child Health. 2015;2:169.

49. Abebe FE, Gebeyehu AW, Kidane AN. Factors leading to caesarean section at Felegehiwot referral Hospital, Northwest Ethiopia: : a retrospective record review. Reprod Health. 2016;13:6.

50. Central swastika agency: Southern Nations, Nationalities and Peoples' Region; 2007.

51. Fesseha N, Getachew A, Hiluf M, et al. A national review of cesarean delivery in Ethiopia. Int J Gynaecol Obstet. 2011;115(1):106-111.

52. Bago BJ. Prevalence and Its Associated Factors among Women Undergone Operative Delivery at Hawassa University Comprehensive Specialized Hospital, Southern Ethiopia. Gynaecol Obstet. 2017;8:461 